MATEC Web of Conferences 22,04021 (2015)

DOI: $10.1051 /$ matec conf/ 20152204021

(C) Owned by the authors, published by EDP Sciences, 2015

\title{
Analysis of Deflection Problems of Large-span Continuous Rigid Frame Bridge and Prevention Measures
}

\author{
Dong Chen* \& Yaxun Yang \\ Highway College, Chang'an University, Xi'an, Shaanxi, China \\ Peng Liu \\ Highway College, Chang'an University, Xi'an, Shaanxi, China
}

\begin{abstract}
The large-span continuous rigid frame bridge is a kind of common structural form in long-span bridges of our country, but one of the main diseases of these bridges is the excessive deflection in the mid-span, which seriously affects the safety of the structure. This paper makes a comprehensive analysis for the causes of the excessive deflection, and lists the commonly-used control measures in engineering. Simultaneously, new improvement measures and the comparative analysis of before-and-after improvements are put forward on this basis. However, these measures can be used to inhibit deflection in a certain extent, but cannot avoid the occurrence of deflection completely.
\end{abstract}

Keywords: continuous rigid frame bridge; excessive deflection in the mid-span; cause; prevention measures

\section{INTRODUCTION}

The prestressed concrete continuous rigid frame bridge has advantages such as stronger stiffness, good integrality, convenient construction driving comfort, and beautiful line shape. Therefore, it has been widely used and developed in China and become one of the most common long-span concrete bridge types since 1980s.

However, with the increase of bridge span, problems about the continuous rigid frame bridge during the using process are gradually highlighted. At present, there are two main diseases of these bridges at home and abroad: the excessive deflection in the mid-span and the crack in box girder. The deflection could intensify the box-girder cracking, and the increasing cracks in box girder reduce the stiffness of the structure, and further aggravate the deflection in the mid-span. Both diseases influence each other and form a vicious spiral.

A few researches with a main span of excessive mid-span deflection of bridge at home and abroad are listed as follows.

The auxiliary channel bridge of Humen Bridge is a three-span continuous rigid frame bridge, and the spanning arrangement is $150 \mathrm{~m}+270 \mathrm{~m}+160 \mathrm{~m}$. It is opened to traffic in 1997. From the inspection in 2003, we found that, compared with a linear bridge, the downwarping of the left amplitude bridge is $22.2 \mathrm{~cm}$, and the downwarping of the right amplitude bridge is $20.7 \mathrm{~cm}$. At the same time, through some existing in the vertical cracks and a small amount of the principal tensile stress of diagonal crack the deflection of two amplitudes is shown in Figure 1.

The Parrots Bridge in California, USA is a three-span prestressed concrete continuous rigid frame bridge. The span is $99 m+195 m+99 m$. It is opened to traffic for 12 years. The monitoring data showed that the main span deflection occurred in obvious cross, the downwarping amounts to $635 \mathrm{~mm}$, and 1/307 span length of paper. It is shown in Figure 2.

The long-span continuous rigid frame bridge stretching across the middle and lower flexible can jeopardize more than lead to the significantly increasing cost of bridge maintenance. Once the bridge damage occurs, it can reduce the operation and structure of traffic safety more serious. So, the mid-span deflection problem has become a problem to be solved in the process of bridge construction and the development of long-span continuous rigid frame.

\section{ANALYSIS THE REASONS OF THE EXCES- SIVE DEFLECTION}

\subsection{Shrinkage and creep of concrete}

The concrete shrinkage and creep of concrete has been considered to be a major cause of long-term deflection.

The concrete structure is composed of a variety of materials, and the theory of the design parameters and actual parameters are quite different. Therefore, the concrete shrinkage and creep effect of uncertainty is the biggest obstacle of long-span rigid frame bridge's long-term deflection prediction

In recent years, with the devolopment of high strength and early strength concrete, the research of creep and shrinkage of concrete has become more and more complex. Besides, the long-span continuous

*Corresponding author: 1063660398@,qq.com

This is an Open Access article distributed under the terms of the Creative Commons Attribution License 4.0, which permits unrestricted use, distribution, and reproduction in any medium, provided the original work is properly cited. 


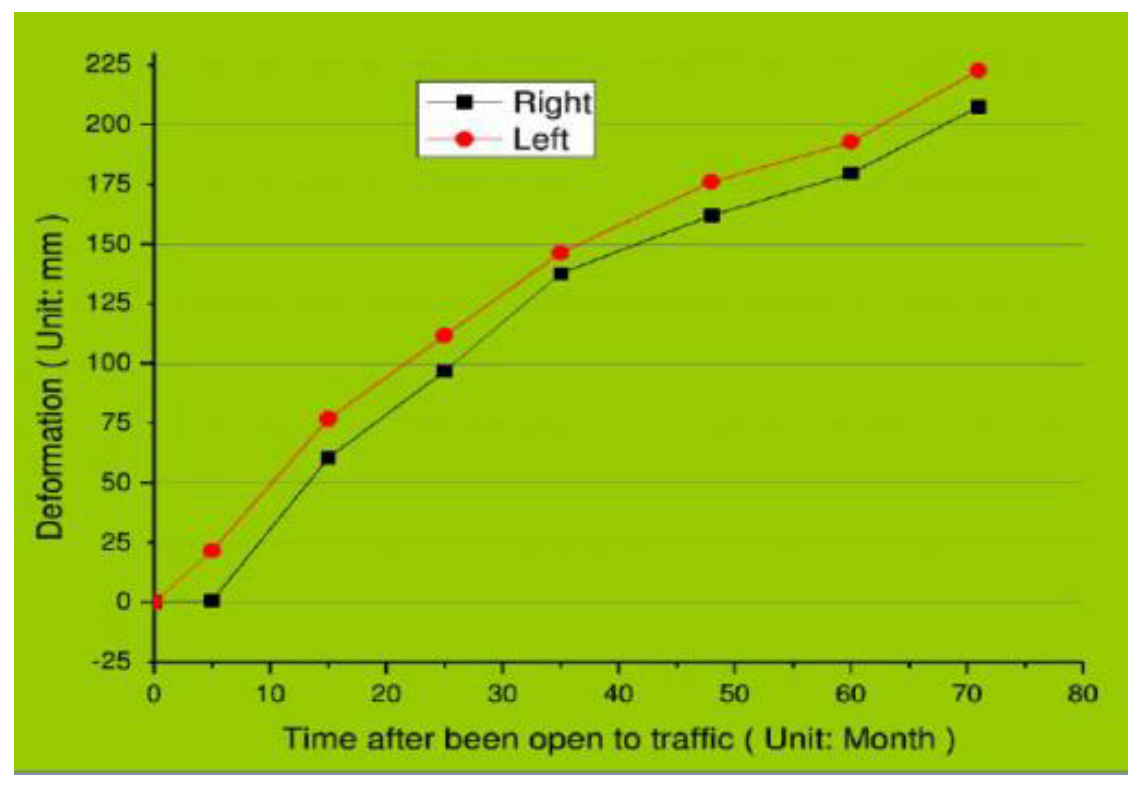

Figure 1. Deflection line chart of Humen Bridge

rigid frame bridge uses the pumping cantilever casting, high strength concrete, large water-cement ratio, various additives (such as the water reducing agent, the retarder and the early strength agent) and more. The box section is more and more light, thinner, and having great effects on the concrete shrinkage and creep characteristics; it strengthens the concrete shrinkage and creep influence on the structure.

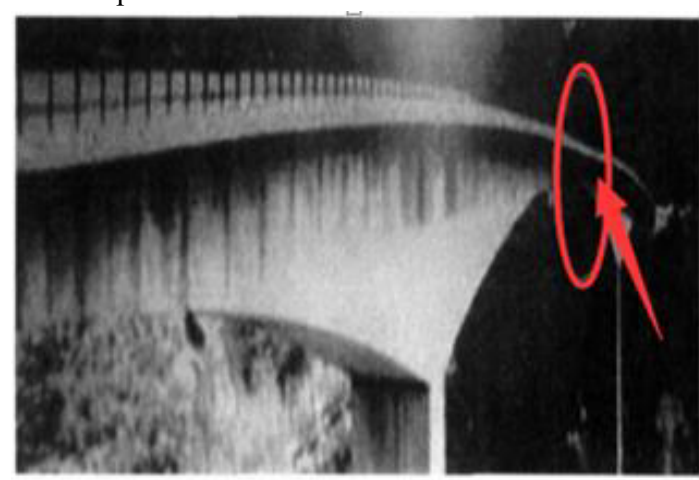

Figure 2. Obvious deflection at midspan of Parrots

\subsection{Change of Stiffness}

The negative moment in the fulcrum will be reduce because of the deflection at mid-span, while reduction of negative moments about dead load in fulcrum is the span of the constant increase in the amount of load positive moment. The excessive creep will lead to the floor of the cross for the positive moment and cracking. In addition, a variety of cracks in the box beam body caused by other factors will also produce the main beam stiffness which is weakened, leading to further intensifying the deflection of beam body. The general structure of the severe cracking deflection value is relatively large. For example, the main span of the bridge is $245 \mathrm{~m}$ in Huangshi, there are hundreds of cracks, the mid-span deflection and larger value of span is $320 \mathrm{~mm}$. And the crack of secondary channel bridge of Humen Bridge is very few, the deflection value of it is only $220 \mathrm{~mm}$, and it is far less than the Huangshi Bridge.

\subsection{Prestress loss of longitudinal steel}

The serious longitudinal prestress loss will lead to a great reduction in structure prestressed degree of full bridge, the structure stiffness decreases, and the deflection at mid-span. At the same time, it will cause the vertical cracks and reduce the ability of the beam body against the principal tensile stress.

The prestress loss is so large that it will result in the decrease of the effective stress and deformation of prestressed to offset load, so that the main beam cracks with the passage of time can further increase the prestress loss of concrete creep which leads to increasing the long-term deflection of bridge. The research shows that the bridge into different stages, the reduction of effective prestress in the roof beam, the bottom beam and the plate beam cause the increase about deflection, but the degree of influence of different roof beam of the bridge and the maximum deflection increase of prestress loss are followed by the web beam and the minimal impact of bottom beam.

In addition, because the prestress loss of longitudinal prestress is caused by shrinkage and creep which can result in box-girder web inclined crack and crack- 
ing disease, it has also become a problem in the continuous rigid frame bridges.

In conclusion, the influence of prestress loss on the long-term deflection of large-span prestressed concrete rigid frame bridge is obvious, which is mainly because the prestress loss and the prestress and load effects do not match. The difference between the two is constantly expanding, which results in the increase of long-term deflection of bridge.

\subsection{Construction quality}

The overall level of construction quality in China is not very high. Due to construction errors in the construction process, the actual prestress value is less than the designed prestress value. In the construction, although early strength agent can improve the early strength of concrete, its elastic modulus is still low, and the tensioning prestress that can make the prestress loss is too large. The continuous rigid frame bridge is usually a cantilever placing construction, the construction process and the quality of the continuous rigid joints have a significant impact on the overall stiffness of the bridge structure. Quality problems in the actual construction of a considerable number of vertical cracks, such as the early form removal, the density difference between the seams of concrete, the cutting hair deep enough vertical joints and so on affect the quality and reduce the overall main beam stiffness. In addition, the construction camber design, maintenance, and the heat-insulating humid-holding measures are not only inadequate, but also for the development of the cracks and deflection lay hidden.

\subsection{Poor management}

With the rapid development of China's economy, traffic conditions have been greatly improved. With the rapid increase of traffic volume, the actual traffic in many bridges is far more than the traffic required by design. Because management is not perfect and a lot of overload overweight vehicle go through the bridge, so the bridge is seriously overloaded. With time passing by, there are the crack and deflection in bridge, thereby reducing the stiffness of the beam cross-section, resulting in lower span deflection. The maintenance and the bridge health inspection by the bridge management personnel are not timely. Small cracks, repaired unseasonal, erosion by rain, overloading and other effects of fractures cause the deflection at span and endanger the safety of the structure.

\section{MEASURES OF CONTROL THE EXCESSIVE DEFLECTION AT MID-SPANPREPARING THE NEW FILE WITH THE CORRECT TEMPLATE}

From the above analysis, it shows that the deflection in the long-span continuous rigid frame bridge is caused based on many factors, so the measures of control the excessive deflection at mid-span must be used to improve the overall mechanical properties of the bridge and compensate the prestress loss, thereby improving the strength and stiffness of the structure, making the working conditions of the bridge improve significantly. At the same time, to repair cracks, inhibit the deterioration of original cracks and enhance the durability of structures, this paper lists several commonly-used methods in engineering, and puts forward a new technology.

\subsection{Strengthened by external prestressing}

The main factor of the excessive deflection in the long-span continuous rigid frame bridge is the prestress loss. Therefore, the quite commonly-used reinforcement methods and more obvious way now in the engineering are strengthened by external prestressing. This method not only can improve the structure of prestressing degree and compensate the prestress loss, but also can partially restore distortion and prevent it to cross deflection at middle span. What's more, strengthened by external prestressing, it can limit and reduce cracks and deformation structure, improve the stiffness of structure and bearing capacity of the structure, and improve the stress state of the structure. There are little interference on the bridge operation construction and operation in the process of construction, and this method has good economic benefits.

\subsection{Sticking steel board method}

The sticking steel board method is another one of the most commonly-used methods of reinforcement. The steel plate is with the epoxy resin paste tension edges or the weak parts of reinforced concrete structures, so that the formation of the original structure as a whole to participate in the force can improve the stress state and the original structure of reinforced concrete, and improve the structure of stiffness, limit the further development of the crack, so as to achieve the purpose of improving the carrying capacity and crack capabilities bridge. And the reinforcement is used in middle span and pier cracking area of floor area, and the bottom of the pier pier top. The sticking steel board method is suitable for the reinforced concrete beam, which is reinforced by a large eccentric compression and tension members that are not used for the plain concrete structures.

\subsection{Carbon fiber adhesion method}

The sticking steel board method will increase the size of the structure to a certain extent, increase the weight of the structure and the stiffness change, lead to the structure internal force redistribution by means of mechanical equipment in the construction, especially in the high altitude operation with a certain degree of difficulty and danger. The carbon fiber cloth reinforcement can be done manually and has good corrosion resistance or no corrosion phenomenon after the reinforcement plate. Since 1980s, the carbon fiber as a 


\section{MATEC Web of Conferences}

new type of material is more and more applied in civil engineering. At present, the carbon fiber reinforced concrete structure has been widely studied both in theory and practice, and it has made great progress The advantages of carbon fiber with high strength, light weight, strong corrosion resistance, easy construction. Therefore, this method as a new method of structural strengthening technology has been widely used in the area of reinforcement.

\subsection{New method}

The basic reason of girder deflection is the decrease of stiffness about the main beam. Many large-span continuous rigid frame bridges are designed by variable height. The bridge plate is generally used or parabolic curve design, so the fulcrum beam height is large, its stiffness is great and the stiffness of mid-span beam height is very small. The mid span is a weak position about deflection. In order to reduce the deflection and improve the structure stiffness, the most commonly-used method of reinforcement is the sticking steel board or the carbon fiber in project. However, sometimes, that in the lower part of the bridge's construction is difficult, and have higher risk. So it can be considered to install the steel truss in the upper bridge to improve the stiffness of the structure.

In this paper, a continuous rigid frame bridge with span of $65+130+65 \mathrm{~m}$ is regarded as an example. The special bridge structure analysis program Midas/Civil is adopted to establish the finite element model for structural internal force calculation and checking. The finite element model has 139 nodes, 143 beam elements, and it is shown in Figure 3 and Figure 4. The truss is a steel truss and symmetrically arranged in cross-span bridges within $40 \mathrm{~m}$ range. The pipe size is that $\mathrm{D}=30 \mathrm{~cm}$, thickness $\quad \mathrm{t}_{\mathrm{w}}=1.5 \mathrm{~cm}$

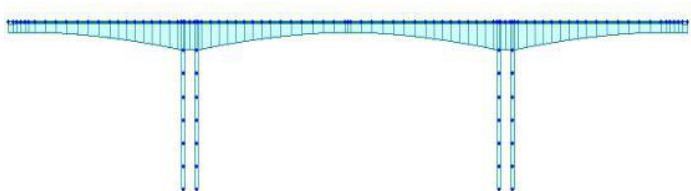

Figure 3. Model without steel truss

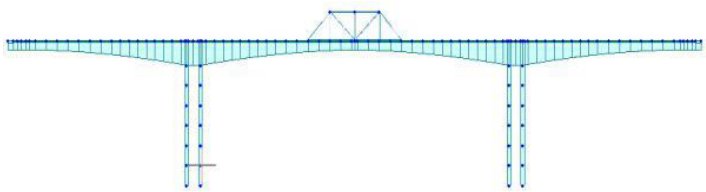

Figure 4. Model with steel truss

In order to estimate the rebar or cross checking, we need to determine the control internal forces of girder along the span direction of each interface. That is, the unfavorable internal forces caused by load were combined in accordance with certain principles. According to the "general code for design of highway bridges and culverts" (JTG D62-2004) that are in accordance with the provisions of the ultimate limit state and serviceability limit state of combination of action effects, it should be designed in the most unfavorable effect combination design. The partial result (envelope) of the short-term effect combination, long-term effect combination, and basic combination are respectively shown in Figure 5 to Figure 10.

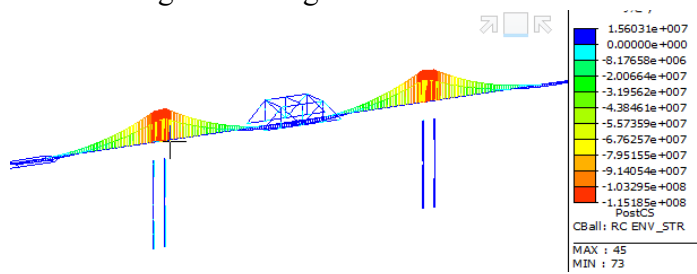

Figure 5. Moment envelope in basic combination

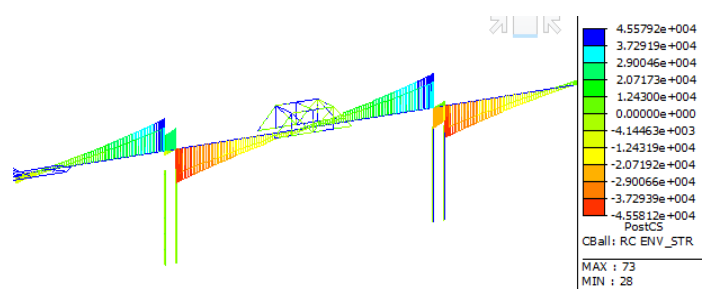

Figure 6. Shear envelope in basic combination

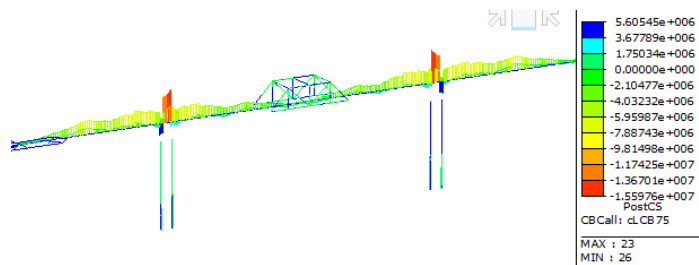

Figure 7. Moment envelope in long combination

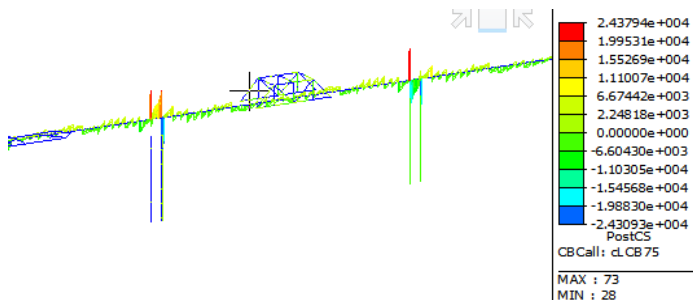

Figure 8. Shear envelope in long combination

The comparison chart of the displacement change based on long-term load is shown in Figure 11 and Figure 12. 
ICETA 2015

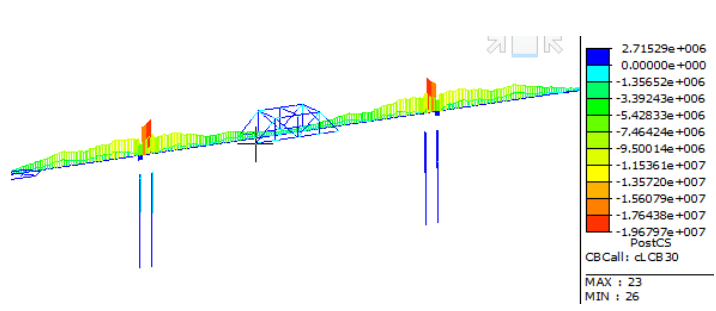

Figure 9. Moment envelope in short combination

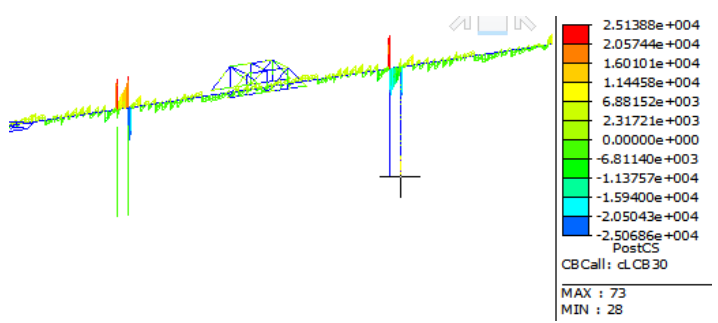

Figure 10. Shear envelope in short combination

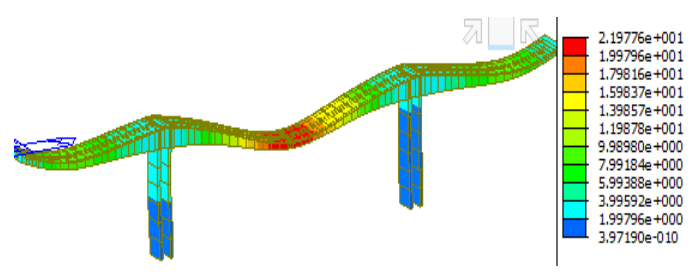

Figure 11. Displacement change without steel truss

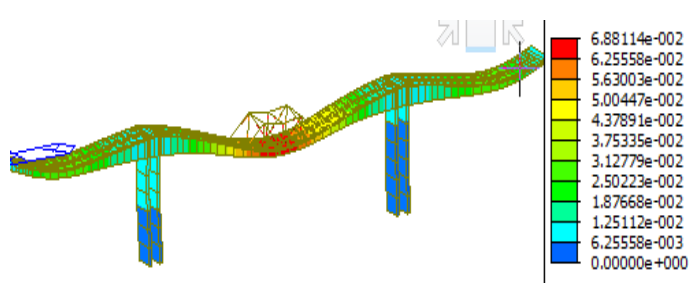

Figure 12. Displacement change with steel truss

Compared Figure 9 with Figure 10, we can know that the deflection at the mid-span is decreased after installing steel truss in the upper bridge, and the disease of the deflection has been improved to some extent. The rate of decrease at midspan is shown in Table 1 and the comparison line chart of the displacement change is shown in the Table 2.

This improvement is based on the original and completed the construction of the bridge, so there is no need to estimate and arrange the prestressed tendons again and check the structure directly. Calculation results show that all indexes meet the design requirements.

Table 1. Rate of decrease at midspan
\begin{tabular}{|l|l|l|l|}
\hline Node & $\begin{array}{l}\text { without } \\
\text { truss(cm) }\end{array}$ & with truss(cm) & $\begin{array}{l}\text { The rate of } \\
\text { decrease (\%) }\end{array}$ \\
\hline 40 & -3.6 & -3.5 & 2.6 \\
\hline 41 & -3.88 & -3.73 & 3.9 \\
\hline 42 & -4.03 & -3.8 & 5.7 \\
\hline 43 & -3.51 & -3.2 & 8.8 \\
\hline 44 & -2.91 & -2.55 & 12.4 \\
\hline 45 & -1.72 & -1.33 & 22.5 \\
\hline 46 & -1.92 & -1.53 & 20.2 \\
\hline 47 & -1.71 & -1.33 & 22.5 \\
\hline 48 & -2.91 & -2.55 & 12.4 \\
\hline 49 & -3.51 & -3.2 & 8.9 \\
\hline 50 & -4.02 & -3.79 & 5.8 \\
\hline 51 & -3.88 & -3.72 & 4 \\
\hline 52 & -3.59 & -3.5 & 2.7 \\
\hline 53 & -3.23 & -3.17 & 1.8 \\
\hline
\end{tabular}

Table 2. Comparison line chart of the displacement change

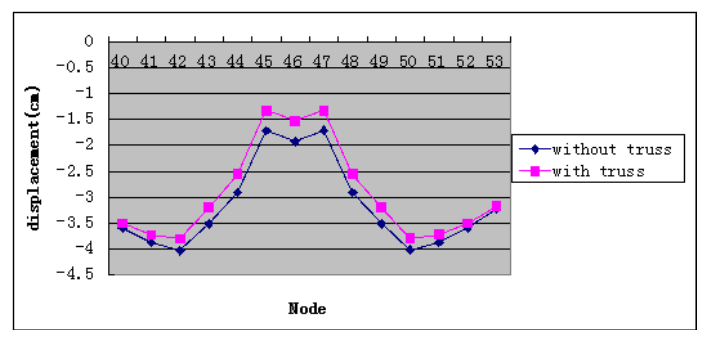

Conclusion:

(1) From the above comparison chart and analysis of available data, we can see that the reinforcement measure can reduce the deflection of main girder at mid-span in a certain extent,and the rate of decrease at midspan section can reach more than $20 \%$.

(2) The decreasing rate of deflection at middle span is relatively large by using this measure. The reinforcement effect is obvious, so it can play a significant role in practice.

(3) The checking results meet the design requirements. We can use the lightweight truss structure in the actual project to reduce the influence about weight of truss to original structure. So this measure has the effect of reinforcement and has certain practical significance in practical engineering.

\section{CONCLUSION}

There are such problems existing in engineering of long-span continuous rigid frame bridges as web plate cracking and mid-span deflection influenced by many factors, so to solve this problem. First, we should understand the stress condition of the bridge structure, consider various situations and determine the structure of the current stress state by calculation and analysis; 


\section{MATEC Web of Conferences}

strengthening the structure should be designed to restore longitudinal prestressing and improve the stiffness as the goal to ensure that the effect of reinforcement can meet the requirements of the structural force.

In addition, the stress of bridge substructure will change, which should be also considered when reinforcing. The improvement measures in a certain extent can inhibit the excessive deflection, but cannot avoid the long-span continuous rigid frame bridge deflection occurring. Therefore, the long-span continuous rigid frame bridge should be regularly detected, and have real-time monitoring of the development trend of mid-span deflection and take remedial measures in a timely manner to nip in the bud.

\section{ACKNOWLEDGEMENT}

I would like to express my gratitude to all those who helped me during the writing of this thesis.

My deepest gratitude goes first and foremost to Professor Yang Yaxun, my supervisor, for his constant encouragement and guidance. He has walked me through all the stages of the writing of this thesis. Each step is completed under the guidance of tutor and the massive painstaking care of supervisor has been poured into from this thesis's establishment to completion. In this tutorial, I would like to pay tribute and heartfelt thanks to him! Without his consistent and illuminating instruction, this thesis could not be accomplished as its present form.

Second, I would like to express my heartfelt gratitude to my roommate, Wang Kaihua and Cao Shulong who guide me to translate this paper in Chinese into the English. And I had learned much knowledge of English, especially the specialized English in Civil Engineering.

Last but not least, I want to thank my beloved family for their loving considerations and great confidence in me all through these years. I also owe my sincere gratitude to my friends and my fellow classmates who gave me their help and time in listening to me and helping me work out my problems during the difficult course of this thesis.

\section{REFERENCES}

[1] Hanfan Xiang \& Lingsen Yao. Advanced Bridge Structure Theory, Ben Jing: China Communications Press Publications.

[2] Jianshu Ye, 2012 the Principle of Structural Design, BenJing China Communications Press Publications.

[3] Xinqi Meng. Lunhua Wei \& Jinchen, Zhanget al: long-span rigid frame bridge midspan research Deflection, World bridges, 41(2):76-79.

[4] Hao Chen, Huanxiong, Mao \& Daolai, Qu. Deflection causes analysis and suggestions about Large span continuous rigid frame bridge. Highway Engineering, 37-38

[5] Daxue He \& Shiqiang Hu: long-span PC continuous rigid frame bridge midspan Deflection Analysis and
Prevention Measures, Urban Roads Bridges \& Flood Control, 112-114.

[6] Dongchun Qi. Yongshui, Zhang\&Qiang,Li;Reason Analysis and Counter measures for Excessive Deflection of Mid spanin Long-Span Continuous Rigid Frame Bridges, Chongqing Jiaotong University (Natural Sciences), 26(6): 46-49.

[7] Zhi Zhang: Long-span continuous rigid frame bridge midspan Deflection causes and reinforcement method, Shanxi Architecture, 35 (3): 296-297.

[8] Jinhua,Zou. Haibo,Jiang \& Shiwu,Ouyang. Long-span Continuous Rigid Frame Bridge midspan Deflection Analysis of the causes and effects of reinforcement, Highway, 72-74.

[9] Zihui Deng. Concrete structural design analysis and application of commonly used methods of reinforcement, Architecture and Engineering, 437-439.

[10]Jun,Xie \& Guoliang,Wang \&Xiaohua, zheng. State of Art of Long-term Deflection for Long SpanPrestressed Concrete Box-girder Bridge, Journal of Highway and Transportation Research and Development, 24(1):47-50. 